\title{
Intracystic bleeding of a solitary hydatid cyst: A rare complication of a rare disease in central Africa. A case report
}

\author{
Ankouane Andoulo Firmin ${ }^{1^{*}}$, Ngo Nonga Bernadette ${ }^{2}$, Monabang Catherine ${ }^{3}$, Djapa Roger ${ }^{1}$, \\ Tchoumi Eric $^{1}$, Njoya Oudou ${ }^{1}$, Ndjitoyap Ndam Elie Claude ${ }^{1}$, D. P. McManus ${ }^{4}$, Malonga Eimo ${ }^{2}$ \\ ${ }^{1}$ Department of Internal Medicine, Faculty of Medicine and Biomdical Sciences, University of Yaounde I, Yaounde, Cameroon; \\ *Corresponding Author: ankouaneandoulo@yahoo.com \\ ${ }^{2}$ Department of Surgery, Faculty of Medicine and Biomdical Sciences, University of Yaounde I, Yaounde, Cameroon \\ ${ }^{3}$ Department of Radiology, Faculty of Medicine and Biomdical Sciences, University of Yaounde I, Yaounde, Cameroon \\ ${ }^{4}$ Donald Peter McManus Infectious Disease Division, Queensland Institute of Medical Research, Brisbane, Australia
}

Received 1 March 2013; revised 11 April 2013; accepted 20 April 2013

Copyright (C) 2013 Ankouane Andoulo Firmin et al. This is an open access article distributed under the Creative Commons Attribution License, which permits unrestricted use, distribution, and reproduction in any medium, provided the original work is properly cited.

\begin{abstract}
Splenic cysts are rare lesions and most of them are hydatid in origin. Hydatid disease is very rare in central Africa although it is cosmopolitan in North Africa. We are presenting a case of intracystic bleeding complicated with shock in a rural based Cameroonian and owner of hunting dogs treated in our university teaching hospital.
\end{abstract}

Keywords: Hydatid Disease; Cyst; Bleeding; Splenectomy

\section{INTRODUCTION}

Splenic cysts are rare lesions. Though most often asymptomatic, they can, however, present with pain in the left hypochodrium, which generally herald a complication. In $60 \%-70 \%$ of cases, splenic cysts are hydatid in origin. Hydatid disease is an anthropozoonosis caused by the dog tapworm Echinococcus granulosus. It is cosmopolitan, rampant in the Mediterranean basin of North Africa, in Latin America and in Eurasia [1]. Kenya is the main source of human hydatid disease (cystic echinococcosis) in SubSaharan Africa [1,2]. Few cases have been reported in Central Africa. Cases of spontaneous or post traumatic intraperitoneal rupture of hydatid cysts have been reported. We are presenting the case history of a 40 years old Cameroonian living in a rural area and owner of hunting dogs. He was admitted to the casualty unit of the university teaching hospital, Yaounde, complaining of acute abdominal pain following physical stress complicated by a hypovolemic shock secondary to intraperitoneal bleeding caused by a splenic hydatid cyst. Total splenectomy was performed and post surgery monitoring was uneventful.

\section{CASE HISTORY}

A 40 years old Cameroonian man, living in a rural area and owner of many hunting dogs was admitted to the Yaounde University Teaching Hospital for acute abdominal pain which had been evolving for over 7 days following physical activity and accompanied by vomiting, fever and general body weakness. His past medical history indicated the presence of a splenic cyst diagnosed a year earlier (Figure 1), for which he was given medical treatment (which unfortunately was not documented); hydatid serology at the time was positive.

Physical examination revealed pallor, weakness, fever, a blood pressure of $100 / 50 \mathrm{mmHg}$, a pulse at $98 \mathrm{p} / \mathrm{min}$ and a tender mass at the left hypochondrium (Figure 2). Rectal examination was unremarkable. A full blood count revealed severe anemia with $4 \mathrm{~g} / \mathrm{dl}$ hemoglobin and $1500 / \mathrm{mm}^{3}$ eosinophils but other features were normal. Abdominal ultrasound and CT revealed a large splenic cyst whose content was cloudy (Figure 3). There was no other associated visceral lesion on abdominal imaging, cardiac ultrasound or chest X-ray. On the basis of the acute abdominal pain, hemodynamic instability and severe anemia, a total splenectomy was carried out 48 hours later. He was given Albendazole $\left(\right.$ Zentel $^{\mathbb{B}}$ ) 400 $\mathrm{mg}$ twice daily from the day before surgery to day- 15 after surgery. Post-operatory monitoring was uneventful. Histopathologic analysis of the cystic tissue revealed a univesicular cyst whose wall stained positive on PAS. 


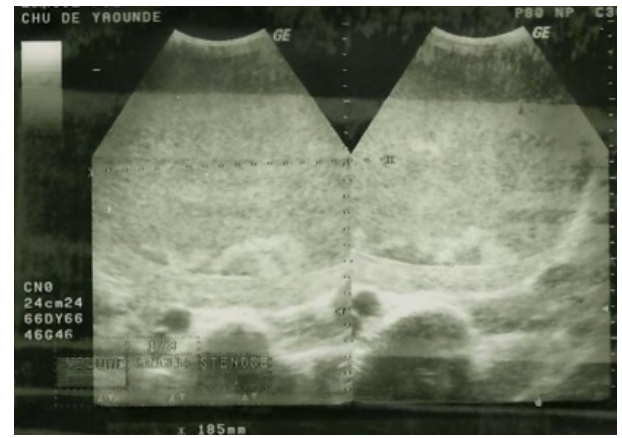

Figure 1. Abdominal US undertaken a year earlier showing the hyper echoic wall of a cyst whose content is hyper echoic.

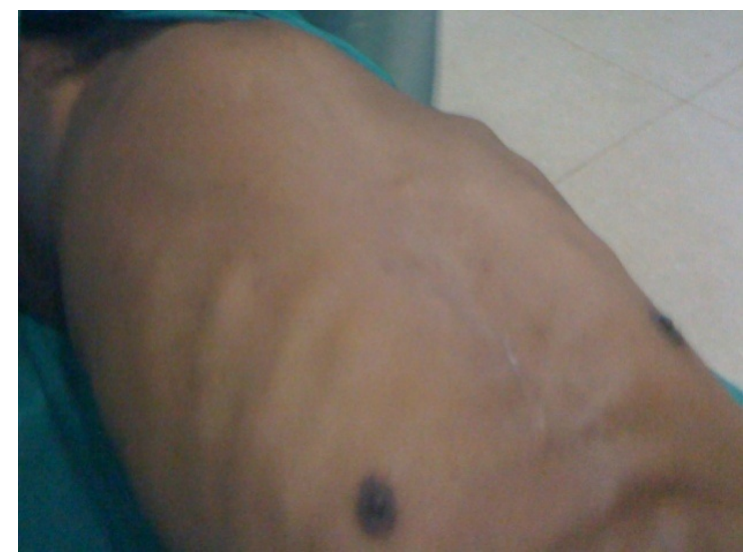

Figure 2. Image of a left hypochondriac swelling, with the patient lying on his back.

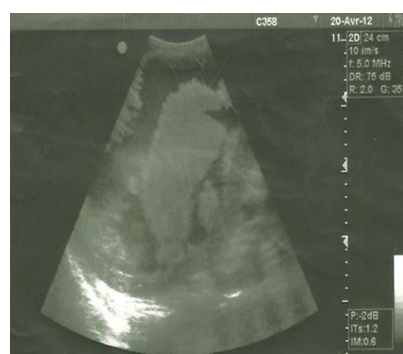

(a)

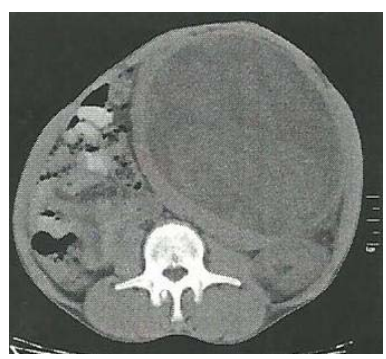

(b)
Figure 3. Abdominal US (a) and a contrast-enhanced CT of the abdomen (b) showing a large splenic mass with well demarcated borders and a cloudy content.

Also present were E. granulosus hooklets and a granulomatous inflammatory reaction with epitheloid and giant cells.

\section{DISCUSSION}

Hydatid disease is a helminthiasis caused by the development in humans of the larval form of E. granulosus. In its classical life cycle, the domestic dog is the final or definitive host while domestic ungulates such as sheep are intermediate hosts. Man occasionally enters the cycle by ingesting eggs of E. granulosus [2]. The spleen is the most common site of infection following hepatic (50\% $70 \%)$ and pulmonary (25\% - 40\%) localizations [2]. It can either occur in isolation or in association with an extrasplenic localization, most often hepatic [2,3]. So far, to the best of our knowledge, intracystic bleeding has never been reported as a complication of hydatid disease. Spontaneous or post traumatic intraperitoneal rupture of the hydatid cyst generally characterizes the natural history of splenic hydatid cysts. Rupture into the peritoneal cavity is rare but remains a life threatening complication $[4,5]$. Small cysts can remain asymptomatic for several years. The clinical features of hydatid disease depend on the affected organ, the diameter of the cyst, its position, its effect on both the infected organ and on neighboring organs, and the eventual presence of complications such as rupture or infection [6]. Acute abdominal pain is the main clinical feature in case of complication [2,4]. Risk factors for rupture of hydatid cysts include trauma, the dimension of the cyst, a superficial localization and the patient's young age [6-8]. In addition to bleeding disorders, these same factors could equally account for intracystic hemorrhage, as is the case with physical stress, a feature of this patient.

Diagnosis is considered on the basis of clinical features, positive serology and imaging tests (particularly abdominal ultrasound and CT-with or without contrast enhancement) [9-12]. In the case of active bleeding, abdominal CT (without contrast enhancement) shows a hyperdense lesion within the cyst. Abdominal ultrasound coupled to a Doppler can rule out an aneurysm or pseudo aneurysm of the splenic artery [9]. Selective arteriography has both diagnostic and therapeutic value in case of massive bleeding. Pseudocysts which follow blunt splenic trauma or splenic infarction must be ruled out [13]. Diagnosis is confirmed by pathologic analysis [2].

Surgery remains the mainstay in the treatment of hydatid cysts of the spleen, especially in case of bleeding [2, 14], although it does not prevent recurrence [15]. It is best in case of large cysts, infection, localization in a vital organ, or in case of complication $[6,15]$. Total splenectomy is indicated in case of large cysts. It also has the advantage of preventing recurrences [2]. Other surgical

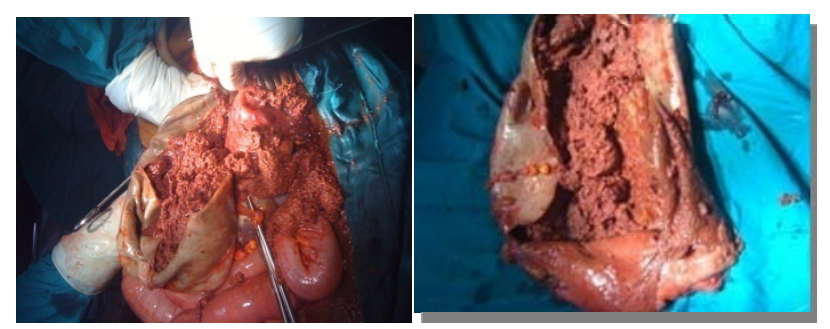

Figure 4. Image showing the hemorrhagic content of the splenic mass (after surgery). 
options exist [6]. Percutaneous treatment (including puncture, aspiration, injection and reaspiration) has been practiced since the 1980s [6,15] but a potential complication is the occurrence of anaphylactic shock which can be minimized by administering the benzimidazole drugs, albendazole or mebendazole [16]. The use of this approach is greatly limited by the type of the presenting lesion, notably types II and IIIb multilocular cysts of the WHOIWGE (Informal Working Group on Echinococcosis) classification (Figure 5) [17]. Deciding on which therapeutic option to use remains challenging [18]. In the ab-

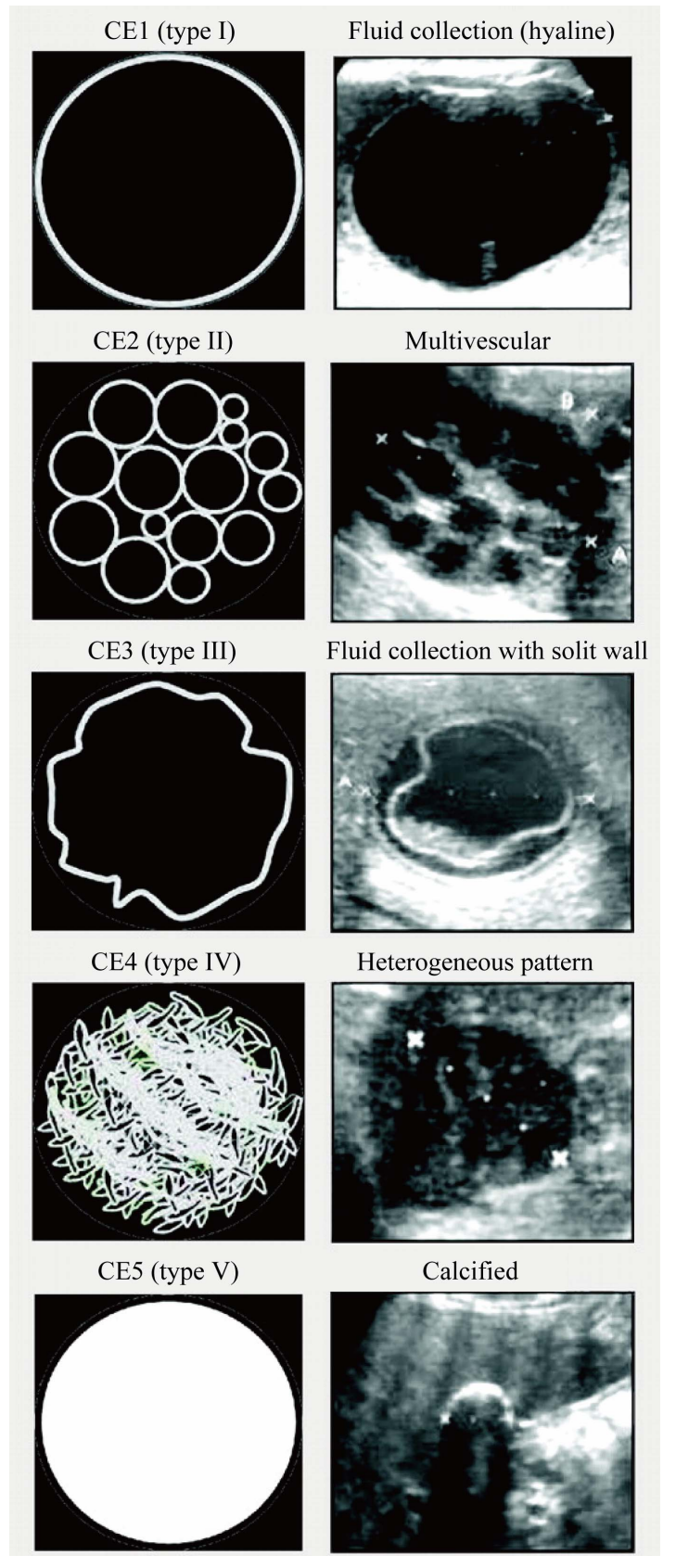

Figure 5. WHO-IWGE Ultrasound classification of CE cysts. With permission from Ref. [6].
Table 1. Suggested stage specific approach to treatment of uncomplicated cystic echinococcosis of the liver. Adapted from Brunetti and colleagues (Elsevier) (Ref. [6]).

\begin{tabular}{|c|c|c|c|c|c|}
\hline $\begin{array}{c}\text { WHO } \\
\text { classification }\end{array}$ & Surgery & $\begin{array}{l}\text { Percutaneous } \\
\text { treatment }\end{array}$ & $\begin{array}{c}\text { Drug } \\
\text { treatment }\end{array}$ & $\begin{array}{c}\text { Suggested } \\
\text { treatment }\end{array}$ & $\begin{array}{c}\text { Resource } \\
\text { setting }\end{array}$ \\
\hline \multirow{4}{*}{ CE1 } & \multirow{4}{*}{ No } & \multirow{4}{*}{ Yes } & \multirow{4}{*}{ Yes } & $\begin{array}{l}\quad<5 \mathrm{~cm}: \\
\text { albendazole }\end{array}$ & Optimal \\
\hline & & & & $<5 \mathrm{~cm}$ : PAIR & Minimal \\
\hline & & & & $\begin{array}{l}>5 \mathrm{~cm} \text { : PAIR } \\
+ \text { albendazole }\end{array}$ & Optimal \\
\hline & & & & $>5 \mathrm{~cm}:$ PAIR & Minimal \\
\hline \multirow[t]{2}{*}{ CE2 } & \multirow[t]{2}{*}{ Yes } & \multirow[t]{2}{*}{ Yes } & \multirow[t]{2}{*}{ Yes } & $\begin{array}{l}\text { Other PT + } \\
\text { albendazole }\end{array}$ & Optimal \\
\hline & & & & Other PT & Minimal \\
\hline \multirow{4}{*}{ CE3a } & \multirow{4}{*}{ No } & \multirow{4}{*}{ Yes } & \multirow{4}{*}{ Yes } & $\begin{array}{l}<5 \mathrm{~cm}: \\
\text { albendazole }\end{array}$ & Optimal \\
\hline & & & & $<5 \mathrm{~cm}:$ PAIR & Minimal \\
\hline & & & & $\begin{array}{l}>5 \mathrm{~cm} \text { : PAIR } \\
+ \text { albendazole }\end{array}$ & Optimal \\
\hline & & & & $>5 \mathrm{~cm}:$ PAIR & Minimal \\
\hline \multirow[t]{2}{*}{ CE3b } & \multirow[t]{2}{*}{ Yes } & \multirow[t]{2}{*}{ Yes } & \multirow[t]{2}{*}{ Yes } & $\begin{array}{l}\text { Non-PAIR PT } \\
+ \text { albendazole }\end{array}$ & Optimal \\
\hline & & & & Non-PAIR PT & Minimal \\
\hline CE4 & & & & $\begin{array}{c}\text { Watch and } \\
\text { wait }\end{array}$ & Optimal $^{*}$ \\
\hline CE5 & & & & $\begin{array}{c}\text { Watch and } \\
\text { wait }\end{array}$ & Optimal ${ }^{*}$ \\
\hline
\end{tabular}

"Minimal may not be applicable here because in low resourced remote endemic areas it may be impossible or too expensive to travel to the nearest hospital just to obtain a diagnosis. PAIR = puncture, aspiration, injection, reaspiration; $\mathrm{PT}=$ percutaneous treatment.

sence of complications, the benzimidazoles remain a good alternative to invasive surgery and percutaneous treatment. Albendazole at $10 \mathrm{mg} / \mathrm{kg}$ twice daily (generally $400 \mathrm{mg}$ ) remains the preferred regimen (Table 1) [6,19].

In conclusion, intracystic bleeding of a splenic hydatid cyst caused by E. granulosus is a rare clinical entity. It should be considered in the setting of an acute abdomen in every patient carrying a hydatid cyst, especially in highly echinococcosis-endemic zones.

\section{REFERENCES}

[1] Eckert, J. and Deplazes, P. (2004) Biological, epidemiological, and clinical aspects of echinococcosis, a zoonosis of increasing concern. Clinical Microbiology Reviews, 17, 107-135. doi:10.1128/CMR.17.1.107-135.2004

[2] Ousadden, A., Raiss, M., Hrora, A., AitLaalim, S., Alaoui, M., Sabbah, F., Benamar, A. and Ahallat, M. (2010) Kystes hydatiques de la rate: Chirurgie radicale ou conservatrice? Pan African Medical Journal, 5, 21.

[3] Tarnoveţchi, C. and Aprodu, G.S. (2010) Multiple abdominal hydatid disease. Case report. Revista Medico- 
Chirurgicala a Societatii de Medici si Naturalisti din Iasi, 114, 152-156.

[4] Derici, H., Tansug, T., Reyhan, E., Bozdag, A.D. and Nazli, O. (2006) Acute intraperitoneal rupture of hydatid cysts. World Journal of Surgery, 30, 1879-1883.

[5] Martino, A., Rampone, B., Schiavone, B., Viviano, C., Cuomo, O., Iovine, L., Sacco, M., Maharajan, G. and Confuorto, G. (2010) Traumatic rupture of hepatic hydatid cyst. Il Giornale di Chirurgia, 31, 401-403.

[6] McManus, D.P., Gray, D.J., Zhang, W. and Yang, Y. (2012) Diagnosis, treatment, and management of echinococcosis. BMJ, 344, e3866. doi:10.1136/bmj.e3866

[7] Akcan, A., Sozuer, E., Akyildiz, H., Ozturk, A., Atalay, A. and Yilmaz, Z. (2010) Predisposing factors and surgical outcome of complicated liver hydatid cysts. World Journal of Gastroenterology, 16, 3040-3048. doi:10.3748/wig.v16.i24.3040

[8] Unalp, H.R., Yilmaz, Y., Durak, E., Kamer, E. and Tarcan, E. (2010) Rupture of liver hydatid cysts into the peritoneal cavity. A challenge in endemic regions. Saudi Medical Journal, 31, 37-42.

[9] Turgut, A.T., Akhan, O., Bhatt, S. and Dogra, V.S. (2008) Sonographic spectrum of hydatid disease. Ultrasound $Q$, 24, 17-29. doi:10.1097/RUQ.0b013e318168f0d1

[10] Moro, P. and Schantz, P.M. (2009) Echinococcosis: A review. International Journal of Infectious Diseases, 13, 125-133. doi:10.1016/i.ijid.2008.03.037

[11] Brunetti, E. and Junghanss, T. (2009) Update on cystic hydatid disease. Current Opinion in Infectious Diseases, 22, 497-502. doi:10.1097/QCO.0b013e328330331c

[12] Junghanss, T., da Silva, A.M., Horton, J., Chiodini, P.L. and Brunetti, E. (2008) Clinical management of cystic echinococcosis: State of the art, problems, and perspectives. American Journal of Tropical Medicine and Hy- giene, 79, 301-311.

[13] Alkofer, B., Lepennec, V. and Chiche, L. (2005) Kystes et tumeurs spléniques: Diagnostic et prise en charge. Journal de chirurgie, 142, 6-13. doi:10.1016/S0021-7697(05)80830-0

[14] Cebollero, M.P., Cordoba, E., Escartin, J., Cantin, S., Artiga, J.M. and Escarte, J.M. (2001) Hydatic cyst of spleen. Journal of Clinical Gastroenterology, 33, 89-90. doi:10.1097/00004836-200107000-00027

[15] Brunetti, E., Kern, P. and Vuitton, D.A. (2010) Writing panel for the WHO-IWGE. Expert consensus for the diagnosis and treatment of cystic and alveolar echinococcosis in humans. Acta Tropica, 114, 1-16. doi:10.1016/j.actatropica.2009.11.001

[16] Nasseri-Moghaddam, S., Abrishami, A., Taefi, A. and Malekzadeh, R. (2011) Percutaneous needle aspiration, injection, and re-aspiration with or without benzimidazole coverage for uncomplicated hepatic hydatid cysts. Cochrane Database of Systematic Reviews, 1, Article ID: CD003623.

[17] WHO Informal Working Group on Echinococcosis (2003) International classification of ultrasound images in cystic echinococcosis for application in clinical and field epidemiological settings. Acta Tropica, 85, 253-261. doi:10.1016/S0001-706X(02)00223-1

[18] Brunetti, E., Garcia, H.H. and Junghanss, T. (2009). Cystic echinococcosis: Chronic, complex, and still neglected. PLOS Neglected Tropical Diseases, 5, e1146. doi:10.1371/journal.pntd.0001146

[19] Stojkovic, M., Zwahlen, M., Teggi, A., Vutova, K., Cretu, C.M., Virdone, R., et al. (2009) Treatment response of cystic echinococcosis to benzimidazoles: A systematic review. PLOS Neglected Tropical Diseases, 3, e524. doi:10.1371/journal.pntd.0000524 